\title{
Colonoscopic preoperative localization using submucosal injection of radiolabelled colloid
}

\author{
Carolyn Cho FRACS ${ }^{1}$, Sanjiv Jain FRCPA ${ }^{2}$, Mark Pilbeam PhD FRCPA ${ }^{3}$, \\ Noel Tait FRACS ${ }^{1}$, Andrew Thomson FRACP ${ }^{4}$
}

C Cho, S Jain, M Pilbeam, N Tait, A Thomson. Colonoscopic preoperative localization using submucosal injection of radiolabelled colloid. Can J Gastroenterol 2008;22(7):637-639.

\begin{abstract}
Malignant colonic polyps can be removed endoscopically but surgical resection is sometimes required. However, the polypectomy site can be difficult to locate. Current methods use various tattooing agents, with varying degrees of success. A new technique using preoperative injection of technetium-99m-labelled antimony colloid, with intraoperative localization using a handheld gamma probe, is described. Although unsuccessful in terms of localizing a previously partially resected polyp, the technique itself proved safe and simple, and has some advantages over other endoscopic approaches.
\end{abstract}

Key Words: Colonic polyps; Lymphoscintigraphy; Sentinel lymph node

\section{La localisation préopératoire de polypes dans le côlon à l'aide d'une injection sous- muqueuse d'un colloïde radiomarqué}

\begin{abstract}
Il est possible d'extirper des polypes malins par endoscopie, mais parfois il faut recourir à la résection chirurgicale par la suite. Cependant, le siège de la polypectomie n'est pas toujours facile à localiser. Les méthodes actuelles de localisation utilisent différents colorants de tatouage, qui donnent des résultats variables. Il sera question, dans le présent article, d'une nouvelle technique de localisation des polypes qui comporte, en phase préopératoire, l'injection d'antimoine colloïdal, marqué au technétium 99m, et qui permet, en phase peropératoire, leur localisation à l'aide d'une sonde gamma tenue à la main. Bien que le procédé se soit montré infructueux dans la localisation d'un polype réséqué antérieurement en partie, la technique elle-même s'est révélée simple et sûre, en plus de présenter certains avantages par rapport à d'autres techniques d'endoscopie.
\end{abstract}

$\mathrm{P}^{\mathrm{c}}$ olyps are a common finding during colonoscopy and are present in up to $50 \%$ of people older than 60 years. Malignant polyps are those in which a focus of invasive carcinoma are found, and are comparatively rare. In many cases, these polyps can be adequately treated endoscopically $(1,2)$. Lymphovascular invasion, degree of differentiation and incomplete resection are adverse prognostic factors. Surgical resection is indicated if the colonoscopic resection is histologically incomplete. Wide lymphatic clearance may also be indicated if the presence of lymphovascular invasion is found in an endoscopically resected polyp (3).

When surgery following polypectomy is indicated, accurate localization of the polypectomy site is crucial. However, unlike more advanced adenocarcinomas, the polypectomy site is usually neither visible nor palpable intraoperatively. To improve the accuracy of localization, numerous methods have been used to mark the polypectomy site during repeat preoperative colonoscopy (4-6). However, for various reasons, these techniques are not always successful $(7,8)$. The present case report describes a novel technique using technetium-99m-labelled antimony colloid.

\section{CASE PRESENTATION}

A 66-year-old man underwent screening colonoscopy. During the procedure, a polyp was found in the ascending colon. A polypectomy was performed. Subsequent histopathology revealed a polyp measuring $12 \mathrm{~mm} \times 10 \mathrm{~mm} \times 5 \mathrm{~mm}$, which contained a focus of moderately differentiated adenocarcinoma. The invasive adenocarcinoma extended into the submucosa and was $0.8 \mathrm{~mm}$ from the excision margin. Lymphovascular invasion was also present. A second colonoscopy and definitive surgery occurred nine weeks later. Colonoscopy was performed by the same proceduralist. In the ascending colon, a small, $1 \mathrm{~cm}$ polypoid lesion was located at what was thought to be the same site as the original polyp. Using a disposable varices injector (Cook Australia, Australia), $0.5 \mathrm{~mL}(10 \mathrm{mBq} / \mathrm{mL})$ of technetium-99m-labelled antimony colloid (Dupont Pharmaceuticals Co, USA) was injected submucosally at the site of the polyp. To ensure that the radioactive tracer was placed accurately in the submucosal layer, this injection was 'sandwiched' between two $1 \mathrm{~mL}$ injections of isotonic saline, as previously described by Fu et al (9). No complications resulted from the colonoscopy or injections.

${ }^{1}$ Department of Surgery; ${ }^{2}$ Department of Pathology, The Canberra Hospital and Calvary Hospital and The Australian National University,

Australian Capital Territory; ${ }^{3}$ St John of God Pathology, Ballarat, Victoria; ${ }^{4}$ Department of Gastroenterology, The Canberra Hospital and

Calvary Hospital and The Australian National University, Australian Capital Territory, Australia

Correspondence: Dr Andrew Thomson, Gastroenterology Unit, The Canberra Hospital, PO Box 11, Woden, Canberra, Australian Capital

Territory, Australia 2606. Telephone 026-244-2222, fax 026-281-5179, e-mail andrew.thomson@act.gov.au

Received for publication April 27, 2008. Accepted March 25, 2008 
The patient proceeded directly to surgery. At laparotomy, the site of the polyp was not visible or palpable. There was no evidence of hepatic or peritoneal metastases. A handheld, intraoperative gamma surgical radiation probe (Gammasonics, Australia), henceforth referred to as 'the probe', was used to locate the site of radioactivity in the colon. Before use, the probe was calibrated according to the manufacturer's instructions, and the sampling time was set to $15 \mathrm{~s}$. The background count was five counts every $15 \mathrm{~s}$. Using the probe, a focus of high radioactivity corresponding to the polypectomy site was easily and quickly located in the ascending colon, $40 \mathrm{~min}$ after colonoscopic injection of the radioisotope. The radioactivity count at this site was 2040 counts every $15 \mathrm{~s}$, and it was contained within a small area approximately $1 \mathrm{~cm}$ in diameter, adjacent to the colonic mesentery. No other areas of radioactivity were found within the colon or the abdominal cavity.

A right hemicolectomy was then performed and the specimen was removed from the operative site. The remaining colon and peritoneal cavity were once again checked for radioactivity, and no areas eliciting a count above the background level were identified by the probe. The resected colon was opened, and the small polyp, which had been seen at colonoscopy, was identified. The probe confirmed this area as a site of localized, high radioactivity, and the area was marked with a silk suture. Intraoperative scanning of the specimen mesentery was performed but no 'sentinel lymph nodes' were found. Postoperatively, the patient's recovery was complicated by Haemophilus influenzae pneumonia. This settled after treatment with antibiotics and the patient was discharged on day 8 . Surprisingly, histopathology of the resected right hemicolon showed a residual polypoid tumour $8 \mathrm{~mm} \times 4 \mathrm{~mm} \times 3 \mathrm{~mm}$ in size, which showed no adenomatous change. The rest of the specimen was normal, with no polyps being evident. Two lymph nodes were identified, which were benign.

\section{DISCUSSION}

To our knowledge, the present paper is the first to report the use of submucosally injected, radiolabelled fluid in an attempt to locate a colonic polypectomy site. The absence of adenomatous tissue in the resected specimen suggests that the site injected was not that of the previous polypectomy. The polypectomy site may have healed in the nine weeks between the polypectomy and the hemicolectomy. It may therefore be better to perform localizing procedures sooner following polypectomies in these types of cases. Nonetheless, the technique described was successful in localizing endoscopically identified tissue and is logistically simple; other than the requirement to minimize the time between colonoscopic labelling and surgery, to reduce both the risk of potential diffusion of radioactive tracer away from the polypectomy site and the decay in the radioactivity of the tracer, the half-life of which is $6 \mathrm{~h}$ (10). The 'sandwich' technique, in which the tracer injection is made between two injections of isotonic saline, has two advantages: it reduces the risk of colonic perforation by the needle, with consequent injection and spillage of tracer into the peritoneal cavity; and it increases the accuracy of injection into the submucosa rather than into other layers of the colonic wall (9).

Alternatives to the technique described above include tattooing agents, which have an advantage because they may be injected several days before surgery. However, submucosal tattoos may not be visible at surgery and, conversely, some agents may disperse widely and not remain localized at the injection site $(11,12)$. Tattooing agents can also lead to local complications. Injection of India ink, the most commonly used tattooing agent, can lead not only to submucosal reactions but also mucosal ulceration, necrosis and edema $(11,12)$, and even fat necrosis and phlegmon formation (13). It is not known whether radiolabelled colloid has the potential to cause complications, such as allergic reactions, within the short interval between colonoscopy and surgery. However, this seems unlikely because it has not been seen in other applications of this technology. Other tattooing agents, such as indocyanine green and methylene blue, are not commonly used because they disperse within seven days, and are associated with mucosal ulceration, necrosis and severe inflammatory reactions $(11,12)$. Admittedly, the technique described in the present paper is more logistically demanding than the use of a tattooing agent, because marking must occur within a few hours of surgery. Nonetheless, the technique does have a role, particularly in cases where there is concern regarding potential allergic reactions to tattoo agents. In addition, with the growth of nuclear medicine, suitably labelled anergic fluid is now available at most general hospitals on relatively short notice.

Other localizing techniques include endoscopic placement of metal clips $(5,6)$, intraoperative colonoscopy $(14)$ and immunoscopy (15). Metal clips may fall off soon after placement or be dislodged by extraluminal palpation during surgery, and may not be readily identifiable at laparotomy, even if still attached to the mucosa. Intraoperative colonoscopy has been used, although it prolongs operation time and, in one series (14), a colonoscopist required the assistance of a surgeon to complete the procedure in $40 \%$ of cases. Immunoscopy involves the use of a fluorescein-labelled antibody against carcinoembryonic antigen to differentiate between malignant and benign areas of mucosa. These techniques are not widely available and, in the latter case, are still experimental.

\section{CONCLUSIONS}

Submucosal injection of radiolabelled colloid at colonoscopy can be successfully used as a localizing technique to facilitate surgical resection. This technique has several advantages over conventional tattooing agents, and may have other potential uses in colonic surgery.

DISCLOSURES: The present study had no sources of financial support. It was presented at the Royal Australasian College of Surgeons Annual Scientific Meeting in the Australian Capital Territory, Australia in November, 2002.

\section{REFERENCES}

1. Haggitt RC, Glotzbach RE, Soffer EE, Wruble LD. Prognostic factors in colorectal carcinomas arising in adenomas: Implications for lesions removed by endoscopic polypectomy. Gastroenterology 1985;89:328-36.

2. Kyzer S, Begin LR, Gordon PH, Mitmaker B. The care of patients with colorectal polyps that contain invasive adenocarcinoma. Endoscopic polypectomy or colectomy? Cancer 1992;70:2044-50.

3. The National Health and Medical Research Council. Clinical Practice Guidelines for the prevention, early detection and management of colorectal cancer. Canberra: Commonwealth of Australia, 2005. 
4. Botoman VA, Pietro M, Thirlby RC. Localization of colonic lesions with endoscopic tattoo. Dis Colon Rectum 1994;37:775-6.

5. Ellis KK, Fennerty MB. Marking and identifying colon lesions. Tattoos, clips, and radiology in imaging the colon. Gastrointest Endosc Clin N Am 1997;7:401-11.

6. Ohdaira T, Konishi F, Nagai H, et al. Intraoperative localization of colorectal tumors in the early stages using a marking clip detector system. Dis Colon Rectum 1999;42:1353-5.

7. Lam DT, Kwong KH, Lam CW, Leong HT, Kwok SP. How useful is colonoscopy in locating colorectal lesions? Surg Endosc 1998;12:839-41.

8. Hancock JH, Talbot RW. Accuracy of colonoscopy in localisation of colorectal cancer. Int J Colorectal Dis 1995;10:140-1.

9. Fu KI, Fujii T, Kato S, et al. A new endoscopic tattooing technique for identifying the location of colonic lesions during laparoscopic surgery: A comparison with the conventional technique. Endoscopy 2001;33:687-91.

10. Kollias J, Gill PG, Chatterton B, Raymond W, Collins PJ. Sentinel node biopsy in breast cancer: Recommendations for surgeons, pathologists, nuclear physicians and radiologists in Australia and New Zealand. Aust N Z J Surg 2000;70:132-6.

11. Price N, Gottfried MR, Clary E, et al. Safety and efficacy of India ink and indocyanine green as colonic tattooing agents. Gastrointest Endosc 2000;51:438-42.

12. Lane KL, Vallera R, Washington K, Gottfried MR. Endoscopic tattoo agents in the colon. Tissue responses and clinical implications. Am J Surg Pathol 1996;20:1266-70.

13. Coman E, Brandt LJ, Brenner S, Frank M, Sablay B, Bennett B. Fat necrosis and inflammatory pseudotumor due to endoscopic tattooing of the colon with India ink. Gastrointest Endosc 1991;37:65-8.

14. Brullet E, Montane JM, Bombardo J, Bonfill X, Nogue M, Bordas JM. Intraoperative colonoscopy in patients with colorectal cancer. Br J Surg 1992;79:1376-8.

15. Keller R, Winde G, Eisenhawer C, et al. Immunoscopy - a technique combining endoscopy and immunofluorescence for diagnosis of colorectal carcinoma. Gastrointest Endosc 1998;47:154-61. 


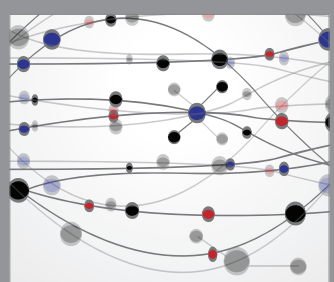

The Scientific World Journal
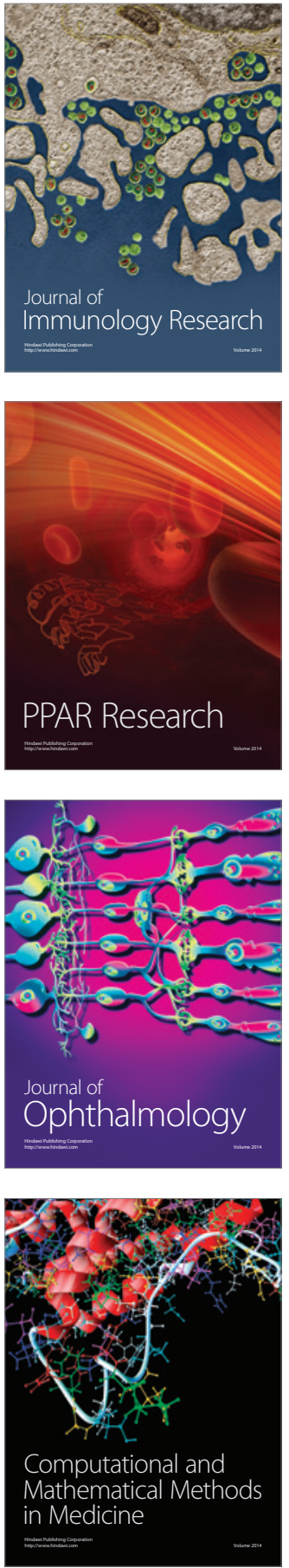

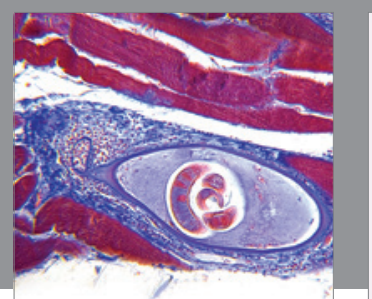

Gastroenterology Research and Practice

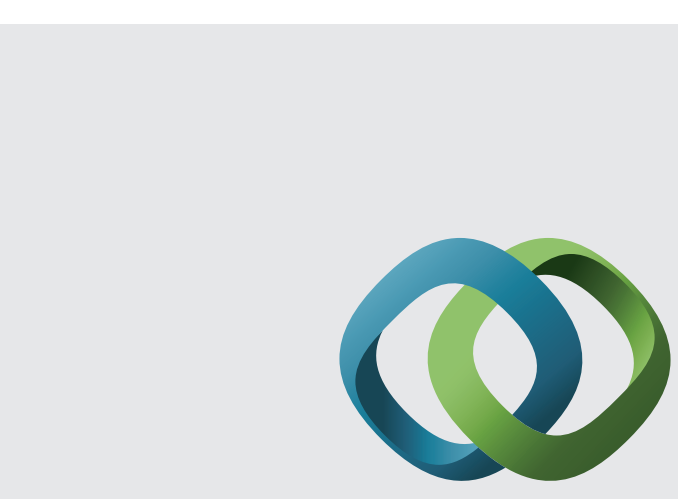

\section{Hindawi}

Submit your manuscripts at

http://www.hindawi.com
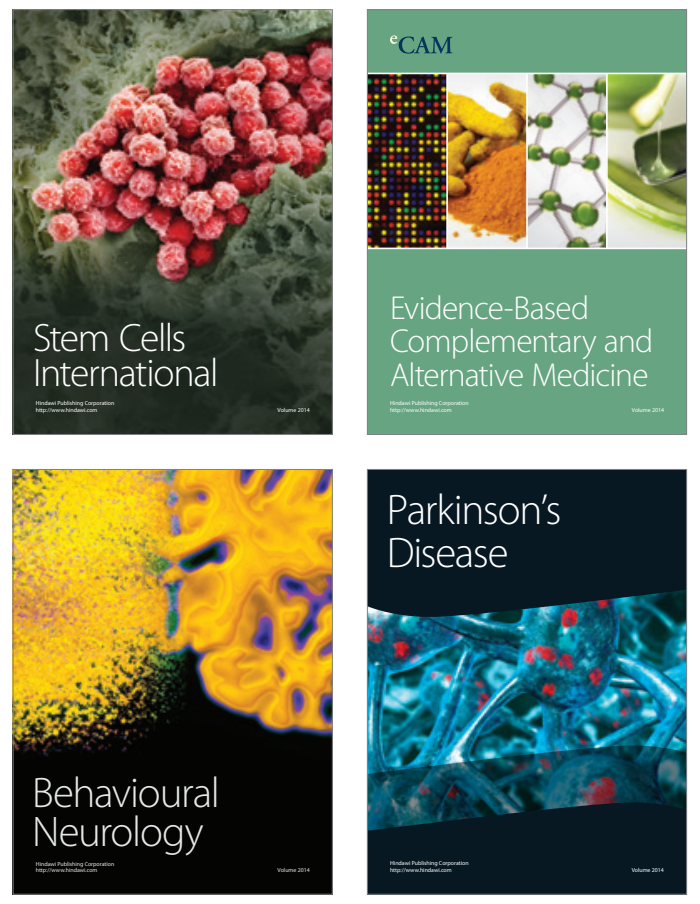
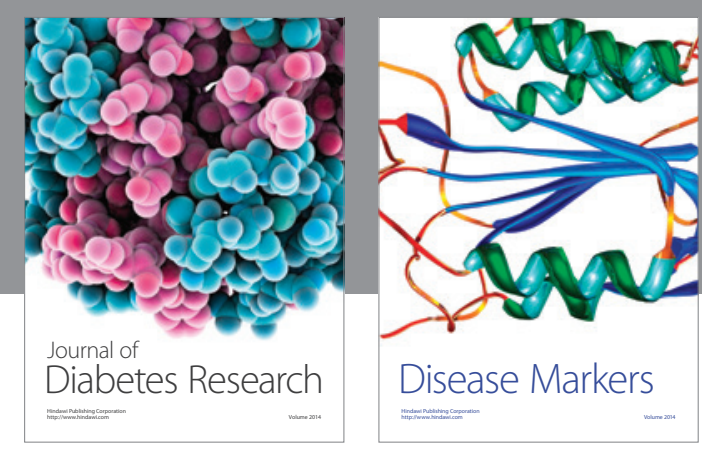

Disease Markers
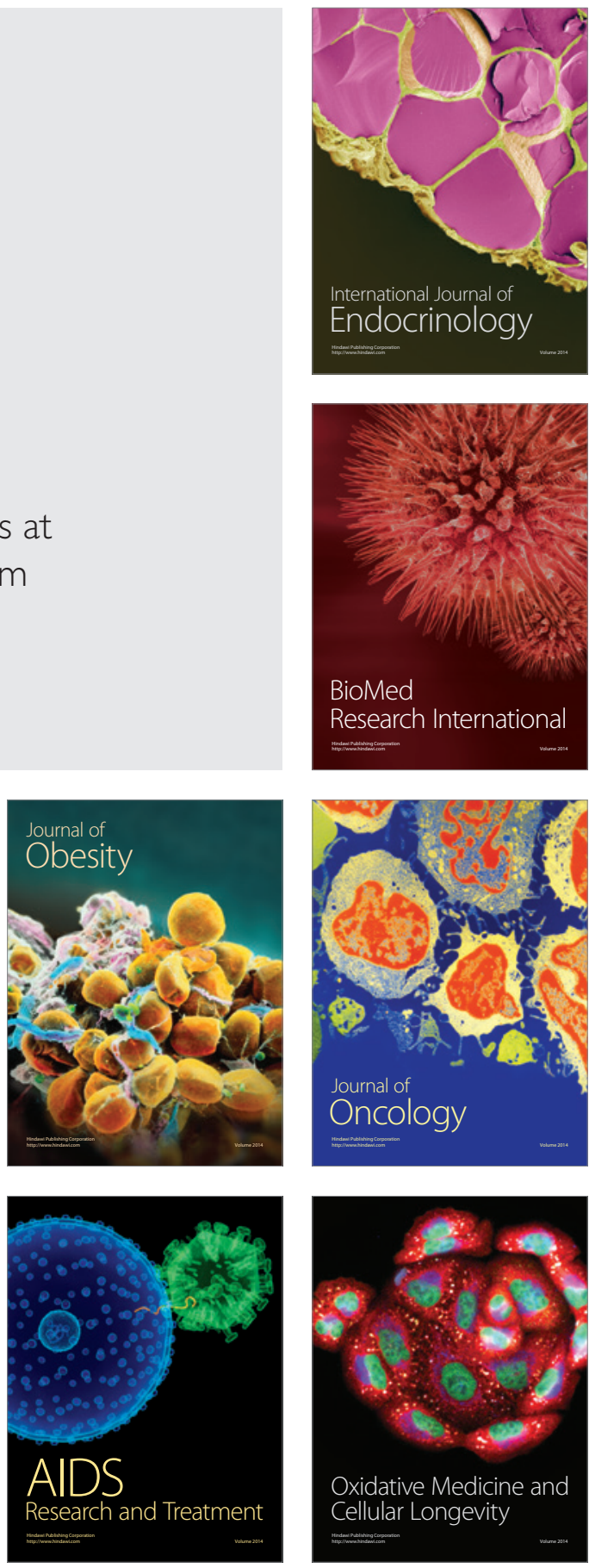